\title{
Sequencing of CDNA from 50 Unrelated Patients Reveals That Mutations in the Triple-Helical Domain of Type III Procollagen Are an Infrequent Cause of Aortic Aneurysms
}

\author{
Gerard Tromp, * Yuli Wu, * Darwin J. Prockop, * Swarna L. Madhatheri, * Caren Kleinert, * James J. Earley, * Jiapiao Zhuang, * \\ Örjan Norrgård," R. Clement Darling, "William M. Abbott, ${ }^{3}$ C. William Cole," Pekka Jaakkola," Markku Ryynänen, ** \\ William H. Pearce, "\# James S. T. Yao, " Kari Majamaa," Stanton N. Smullens, "III Zoran Gatalica, "Robert E. Ferrell, * ** \\ Sergio A. Jimenez, ${ }^{* \neq}$ Charles E. Jackson, ${ }^{\text {sst }}$ Virginia V. Michels, ${ }^{\prime \prime \prime I I}$ Michael Kaye, ${ }^{m}$ and Helena Kuivaniemi * \\ * Department of Biochemistry and Molecular Biology, Jefferson Institute of Molecular Medicine, and "Department of Pathology, \\ Jefferson Medical College, and ${ }^{\prime \prime \prime \prime}$ Department of Surgery, and ${ }^{\ddagger \ddagger}$ Division of Rheumatology, Department of Medicine, Thomas Jefferson \\ University Hospital, Thomas Jefferson University, Philadelphia, Pennsylvania 19107; ${ }^{\ddagger}$ Department of Surgery, University of Umeå, \\ S-90185 Umeå, Sweden; §General Surgical Services, Massachusetts General Hospital, and Department of Surgery, Harvard Medical \\ School, Boston, Massachusetts 02114; "Division of Vascular Surgery, University of Ottawa, Ottawa, Ontario, Canada K1Y 4E9; \\ Departments of "Surgery, and **Obstetrics and Gynecology, University of Kuopio, SF-70211 Kuopio, Finland; ${ }^{\ddagger}$ Division of Vascular \\ Surgery, Northwestern University Medical School, Chicago, Illinois 60611; Department of Neurology, University of Oulu, SF-90220

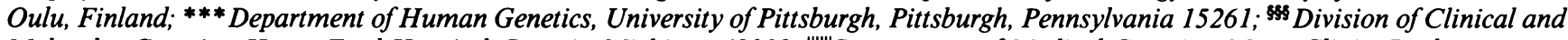 \\ Molecular Genetics, Henry Ford Hospital, Detroit, Michigan 48202; "II!'Department of Medical Genetics, Mayo Clinic, Rochester, \\ Minnesota 55905; and ' Division of Nephrology, The Montreal General Hospital, Montreal, Quebec H3G 1A4, Canada
}

\begin{abstract}
Detailed DNA sequencing of the triple-helical domain of type III procollagen was carried out on cDNA prepared from 54 patients with aortic aneurysms. The 43 male and 11 female patients originated from $\mathbf{5 0}$ different families and five different nationalities. 43 patients had at least one additional blood relative who had aneurysms. Five overlapping asymmetric PCR products, covering all the coding sequences of the triple-helical domain of type III procollagen, were sequenced with 28 specific sequencing primers. Analysis of the sequencing gels revealed only two nucleotide changes that altered the structure of the protein. One was a substitution of threonine for proline at amino acid position 501 and its functional importance was not clearly established. The other was a substitution of arginine for an obligatory glycine at amino acid position 136 . In 40 of the 54 patients, detection of a polymorphism in the mRNA established that both alleles were expressed. The results indicate that mutations in type III procollagen are the cause of only about 2\% of aortic aneurysms. (J. Clin. Invest. 1993. 91:25392545.) Key words: familial aneurysms • polymerase chain reaction • polymorphisms
\end{abstract}

\section{Introduction}

A number of careful studies have shown that aneurysms, even when they are not associated with well-recognized, heritable syndromes such as the Marfan syndrome (1) or Ehlers-Danlos

Address reprint requests to Dr. Helena Kuivaniemi, Department of Biochemistry and Molecular Medicine, Jefferson Institute of Molecular Medicine, Jefferson Medical College, Thomas Jefferson University, 233 South Tenth Street, Philadelphia, PA 19107.

Received for publication 15 October 1992 and in revised form 22 January 1993.

J. Clin. Invest.

(c) The American Society for Clinical Investigation, Inc.

0021-9738/93/06/2539/07 \$2.00

Volume 91, June 1993, 2539-2545 syndrome (EDS) ${ }^{1}$ type IV (1), are frequently familial (2-11). A recent statistical evaluation suggested that aneurysms are caused by defects in a single gene (12). The structural components of arteries and the gene products participating in the proteolysis of the structural components have been suggested as candidate genes for aneurysms (13). Mutations in the fibrillin gene located in chromosome 15 (14) have been shown to cause the Marfan syndrome $(15,16)$. There is a considerable variability in the phenotype among different individuals with the Marfan syndrome within the same family and among different families (17). Fibrillin 15 is, therefore, a potential candidate gene for aortic aneurysms (17). Other candidate genes for aortic aneurysms are collagens and elastin, which are important structural components of the aorta. Their contribution to the strength of an artery was elegantly demonstrated by Dobrin and his co-workers ( 18) by using dog and human cadaver arteries in a system where pressure could be applied onto the artery. Treatment of the artery with collagenase or elastase resulted in a considerable weakness of the structure (18). Several different types of collagens have been isolated from blood vessels, but types I and III collagen are the major components in the arterial wall (19). They are fibril-forming collagens in which three polypeptide chains called the $\alpha$ chains form a stable triple-helical structure $(20,21)$. Each $\alpha$ chain consists of about 340 repeating tripeptide sequences of -Gly-X-Y- in which $\mathrm{X}$ is frequently proline and $Y$ is frequently hydroxyproline $(20,21)$. A recent study on the type III procollagen secreted by cultured skin fibroblasts from patients with aortic aneurysms demonstrated that in 2 out of 14 patients the type III procollagen was thermally unstable when assayed by brief proteinase digestion, suggesting a structural defect in the type III procollagen (22). Furthermore, a mutation in the type III procollagen gene was found in a man who expired at the age of $34 \mathrm{yr}$ from a rupture of the aorta (23). The man had a history of easy bruisability and bleeding, but none of the dramatic skin changes usually associated with type IV EDS $(1,24)$ such as ecchymoses, abnormal scarring, and heavy pigmentation (23). He, therefore,

1. Abbreviations used in this paper: EDS, Ehlers-Danlos syndrome; nt, nucleotide. 
probably presented phenotypic overlap between EDS type IV and familial aneurysms. Subsequently, a mutation in the type III procollagen gene was found in a 37-yr-old woman who had a strong family history of sudden death from ruptured aortic aneurysms (25) without any evidence of EDS type IV or related disorder.

The hypothesis that aortic aneurysms are caused by increased proteolytic activity in the aorta that leads to the weakening of the arterial wall and rupture, has also been supported by several studies (26-29). There are, however, very few, if any, known examples of a gene defect producing an increase in an enzyme activity. It might, therefore, be that the increased proteolytic activity found in aneurysmal aorta is a secondary phenomenon due to some other primary defect.

In conclusion, several candidate genes for aortic aneurysms have been suggested, including $(a)$ fibrillin $15(17),(b)$ collagen $(20,21,30),(c)$ elastin $(31),(d)$ collagenase $(18),(e)$ elastase $(27),(f)$ tissue inhibitor of metalloproteinase (29), and $(g) \alpha_{1}$-antitrypsin (28). In this article we report the detailed DNA sequencing approach to answer the question of whether most aneurysms are caused by mutations in the gene for the type III procollagen.

\section{Methods}

Patient material. Skin biopsy was obtained from all patients listed in Table I after written informed consent. In some cases, blood samples were obtained from family members of the patient after written informed consent. Skin biopsies were used to establish skin fibroblast cultures. Total RNA was isolated from cultured skin fibroblasts with a procedure involving extraction with guanidinium isothiocyanate (32). The RNA was purified by centrifugation on a cesium chloride gradient and used to synthesize first strand of CDNA with MMVL reverse transcriptase (Bethesda Research Laboratories, Gaithersburg, MD). Genomic DNA was isolated from cultured skin fibroblasts or blood on a Genepure 341 automated DNA extractor (Applied Biosystems, Inc., Foster City, CA).

Sequencing of $c D N A$. Sets of oligonucleotides (Table II) based on the cDNA sequence of type III procollagen (33-38) were used as primers so as to generate five overlapping PCR products $(1,2 \mathrm{~A}, 2 \mathrm{~B}, 3$, and 4 in Table II) to cover all the coding sequences for the triple-helical domain of 1029 amino acids of the type III procollagen. Originally, products $2 \mathrm{~A}$ and $2 \mathrm{~B}$ were amplified together as one longer fragment, but since results from DNA sequencing were somewhat variable, the region was divided into two PCR fragments, after which the sequencing results improved. To produce single-stranded DNA sequencing templates, three successive PCRs, of 20 cycles each, were performed for each region.

The first PCR (39) was carried out for 20 cycles in a $30-\mu$ reaction volume containing $0.6 \mathrm{pmol}$ of each primer. $2 \mu \mathrm{l}$ of the first PCR product was used in a second PCR that was carried out for 20 cycles in a $50 \mu$-reaction volume containing $10 \mathrm{pmol}$ of one primer and $2.5 \mathrm{pmol}$ of the other. The third PCR was carried out for 20 cycles in a $100 \mu \mathrm{l}$ reaction volume containing $50 \mathrm{pmol}$ of one primer and $1 \mathrm{pmol}$ of the other primer and $2 \mu \mathrm{l}$ of the second PCR product. The products from the third PCR were run on an agarose gel, and if they were of acceptable quality, additional third PCRs were performed to produce sufficient template DNA for sequencing.

Typically, the final results from the third PCR showed a clean amplification of the desired product on an agarose gel with two bands, one representing the double-stranded DNA and the other representing the single-stranded DNA (not shown). Routinely, cDNA from 10 different cell lines was amplified simultaneously. Water blanks were included in every experiment and they were negative.
The PCR products were purified by adsorption to powdered glass (silica) under high salt conditions using a commercial kit (Geneclean, BIO 101, Inc., Vista, CA). Since adsorption of DNA to silica powder in the presence of $6 \mathrm{M} \mathrm{NaI}$ is pH-dependent ( $\mathrm{pH}$ of $6 \mathrm{M} \mathrm{NaI}$ should be between 6.2 and 7.2 at room temperature), the Nal solution was buffered with $50 \mathrm{mM}$ Pipes and the $\mathrm{pH}$ was adjusted to 6.7 at room temperature with acetic acid. In addition, the $\mathrm{pH}$ of the asymmetric PCR sample was modified by the addition of $1 \mu \mathrm{l}$ of $1 \mathrm{M}$ Pipes, pH 6.7, per $100 \mu \mathrm{l}$ of PCR product. Successful asymmetric PCRs were transferred to microcentrifuge tubes and three volumes of $\mathrm{pH}$-buffered $\mathrm{Nal}$ and $5 \mu \mathrm{l}$ of "Glassmilk" per $100 \mu \mathrm{l}$ of PCR product were added and the mixtures rotated at room temperature. Pelleting and washing of the powdered glass were performed according to the Geneclean kit instructions except that they were performed in an Autogen 540 (an integrated microcentrifuge and pipetting station; Autogen Instruments Inc., Beverly, MA). The pellet was air-dried for $10 \mathrm{~min}$ at room temperature after the final wash and the adsorbed DNA eluted by resuspending the pellet in 5-30 $\mu$ l of water and heating to $65^{\circ} \mathrm{C}$ for $10 \mathrm{~min}$. The powdered glass was pelleted by $20 \mathrm{~min}$ centrifugation and the supernatant transferred to a new tube. Because adsorption of nucleic acids to powdered glass (under the conditions used here) is dependent on length with extremely inefficient adsorption of fragments less than $300 \mathrm{nt}$ in length, the purified asymmetrical PCR products contained almost no PCR primers and were suitable to use as templates in dideoxynucleotide DNA sequencing.

The purified PCR products were sequenced directly with 28 sequencing primers specific for type III collagen (Table III) using Sequenase (U.S. Biochemical Corp., Cleveland, $\mathrm{OH}$ ) or Taq DNA polymerase (Perkin Elmer Cetus, Norwalk, CT) in the dideoxynucleotide method (40). The sequencing was carried out in sets of 12 so that DNA from 10 different cell lines, M13 control DNA and M13 clone containing type III collagen sequences that corresponded to the region in the patient sample, were sequenced simultaneously on a multiwell plate (Earley and Tromp, manuscript in preparation). The reactions were run on $6 \%$ DNA sequencing gels (Sequagel-6, National Diagnostics, Atlanta, GA ). To increase the speed and ease with which the autoradiographs could be interpreted, several reactions terminated with the same dideoxynucleotide were loaded in adjacent lanes (Fig. 1). Typically, the samples from 5-10 patients were loaded so that the blocks of adjacent lanes could be interpreted like a conventional sequence ladder. A significant advantage was that it was easy to identify the appearance of a new band where the other cell lines lacked the band.

Analysis of DNA polymorphisms. Three polymorphic bases at positions nucleotides (nt) 1851, 2092, and 2244 in the coding region of type III collagen were analyzed using genomic DNA as a template in the PCR according to conditions described previously $(41,42 ; \mathrm{Wu}$ and Kuivaniemi, manuscript in preparation). PCR products were then analyzed using allele-specific oligonucleotide hybridization technique or restriction endonuclease digestion as described previously $(41,42 ; \mathrm{Wu}$ and Kuivaniemi, manuscript in preparation ).

\section{Results}

Patient material. DNA sequencing was carried out on type III collagen cDNA from 54 patients with aneurysms. Among the 54 patients there were four pairs of siblings (JIMM408 and JIMM409, JIMM425 and JIMM425a, JIMM425b and JIMM425c, and JIMM425d and JIMM425e in Table I). Thus, the number of unrelated individuals analyzed was 50 , representing $\mathbf{5 0}$ different families. The $\mathbf{5 0}$ unrelated patients were from five different nationalities: 1 Haitian, 3 Finnish, 4 Canadian, 11 Swedish, and 31 U.S. American. Most (43/50) of the patients had at least one blood relative who was also diagnosed with an aneurysm. More specifically, 15 patients had one family member with the disease, 17 patients had two family members, 6 patients had three family members, 2 patients had 
Table I. Clinical Information on Patients

\begin{tabular}{|c|c|c|c|c|c|c|}
\hline Code & Gender & Age* & $\begin{array}{l}\text { Location of } \\
\text { aneurysm }\end{array}$ & Status ${ }^{8}$ & Family" & Nationality \\
\hline JIMM255 & $\mathbf{M}$ & 60 & AAA & $\mathbf{R}$ & $3(2 \mathrm{~B}, \mathrm{~A})^{\prime}$ & Swedish \\
\hline JIMM256 & $\mathbf{M}$ & 64 & AAA, IA & $\mathrm{O}, \mathrm{R}$ & $1(\mathrm{~F})$ & Swedish \\
\hline JIMM263 & $\mathbf{M}$ & 38 & TAA & CT & 0 & Canadian \\
\hline JIMM279 & $\mathbf{F}$ & 50 & IA & O & $2(\mathrm{~S}, \mathrm{~N})^{\prime}$ & Swedish \\
\hline JIMM280 & $\mathbf{M}$ & 55 & AAA & 0 & 0 & Swedish \\
\hline JIMM281 & $\mathbf{M}$ & 60 & AAA & 0 & 0 & Swedish \\
\hline JIMM285 & $\mathbf{M}$ & 54 & AAA, IIA & O & 1 (B) & U.S. \\
\hline JIMM295 & $\mathbf{M}$ & 55 & AAA, IA & $\mathbf{O}, \mathbf{R}$ & $2(2 B)^{\prime}$ & Swedish \\
\hline JIMM296 & $\mathbf{M}$ & 68 & AAA & 0 & 0 & Swedish \\
\hline JIMM332 & $\mathbf{M}$ & 70 & AAA & 0 & 0 & Swedish \\
\hline JIMM334 & $F$ & 67 & AAA & O & 1 (B) & U.S. \\
\hline JIMM335 & $\mathbf{M}$ & 69 & AAA & 0 & 1 (B) & U.S. \\
\hline JIMM335d & $\mathbf{M}$ & 65 & AAA & 0 & 1 (B) & U.S. \\
\hline JIMM335f & $\mathbf{M}$ & 67 & AAA & o & $2(2 S)$ & U.S. \\
\hline JIMM335g & $\mathbf{M}$ & 66 & AAA & 0 & $2(2 B)$ & U.S. \\
\hline JIMM335h & $\mathbf{M}$ & 64 & AAA & O & 1 (B) & U.S. \\
\hline JIMM335i & $\mathbf{M}$ & 73 & AAA & 0 & $2(\mathrm{~B}, \mathrm{~S})$ & U.S. \\
\hline JIMM335j & $\mathbf{M}$ & 67 & AAA & 0 & 1 (B) & U.S. \\
\hline JIMM335k & $\mathbf{M}$ & 65 & AAA & 0 & $2(\mathrm{~B}, \mathrm{~S})$ & U.S. \\
\hline JIMM341 & $\mathbf{M}$ & 73 & AAA & 0 & $1(\mathrm{~S})$ & Swedish \\
\hline JIMM342 & $\mathbf{M}$ & 46 & AAA, IA & $\mathbf{O}, \mathbf{R}$ & $2(\mathrm{~S}, \mathrm{~F})^{\mathrm{I}}$ & Swedish \\
\hline JIMM350 & $\mathbf{M}$ & 66 & AAA & 0 & $1(\mathrm{~B})$ & Swedish \\
\hline JIMM351 & $\mathbf{F}$ & 62 & TAA & $\mathbf{R}$ & $2(\mathrm{~F}, \mathrm{~S})$ & U.S. \\
\hline JIMM396 & $\mathbf{M}$ & 58 & AAA, IIA & 0 & $2(F, B)$ & U.S. \\
\hline JIMM397 & $\mathbf{M}$ & 67 & AAA & 0 & $3(\mathrm{~B}, 2 \mathrm{C})$ & Finnish \\
\hline JIMM398 & $\mathbf{M}$ & 66 & AAA & U & 1 (B) & Finnish \\
\hline JIMM406 & $\mathbf{M}$ & 41 & MAA & $\mathrm{O}$ & $2(\mathrm{D}, \mathrm{B})$ & U.S. \\
\hline JIMM407 & $\mathbf{M}$ & 18 & AAA & $\mathbf{R}$ & - & U.S. \\
\hline JIMM408 & $\mathbf{M}$ & 68 & AAA & - & $5(\mathrm{~F}, \mathrm{G}, \mathrm{A}, 2 \mathrm{~B})$ & U.S. \\
\hline JIMM409 & $\mathbf{M}$ & 63 & AAA & - & $5(\mathrm{~F}, \mathrm{G}, \mathrm{A}, 2 \mathrm{~B})$ & U.S. \\
\hline JIMM419 & $\mathbf{M}$ & 59 & AAA & $\mathbf{R}$ & $3(F, 2 C)$ & U.S. \\
\hline JIMM421 & $\mathbf{F}$ & 47 & AAA & 0 & $4(2 \mathrm{~B}, \mathrm{M}, \mathrm{F})$ & U.S. \\
\hline JIMM422 & F & 85 & AAA & 0 & $3(2 B, F)$ & U.S. \\
\hline JIMM425 & $\mathbf{M}$ & 70 & AAA & $\mathrm{U}$ & 1 (B) & Canadian \\
\hline JIMM425a & $\mathbf{M}$ & 71 & AAA & o & 1 (B) & Canadian \\
\hline JIMM425b & $\mathbf{M}$ & 65 & AAA & $\mathrm{O}$ & 2 (B) & Canadian \\
\hline JIMM425c & $\mathbf{M}$ & 62 & AAA & 0 & 2 (B) & Canadian \\
\hline JIMM425d & $\mathbf{M}$ & 69 & AAA & O & 1 (B) & Canadian \\
\hline JIMM425e & $\mathbf{M}$ & 70 & AAA & $\mathbf{U}$ & 1 (B) & Canadian \\
\hline JIMM425g & $\mathbf{F}$ & 65 & AAA & $\mathrm{U}$ & 1 (B) & Canadian \\
\hline JIMM429 & $\mathbf{F}$ & 77 & AAA & - & $2(2 S)$ & U.S. \\
\hline JIMM430 & $\mathbf{M}$ & - & AAA & 0 & $9(4 \mathrm{~B}, \mathrm{~S}, 2 \mathrm{~A}, 2 \mathrm{C})$ & U.S. \\
\hline JIMM436 & $\mathbf{M}$ & 40 & IA & $\mathrm{O}$ & $4(\mathrm{~S}, \mathrm{~F}, \mathrm{C}, \mathrm{U})$ & U.S. \\
\hline JIMM438 & $\mathbf{M}$ & 63 & AAA & 0 & $1(\mathrm{~B})$ & U.S. \\
\hline JIMM443 & $\mathbf{F}$ & 34 & AAA & 0 & $3(2 \mathrm{~B}, \mathrm{M})^{\prime}$ & U.S. \\
\hline JIMM445 & $\mathbf{F}$ & 68 & AAA & 0 & $2(\mathrm{~F}, \mathrm{~S})$ & U.S. \\
\hline JIMM449 & $\mathbf{M}$ & 59 & AAA & 0 & $2(\mathrm{~B}, \mathrm{M})$ & U.S. \\
\hline JIMM483 & $\mathrm{F}$ & 76 & AAA & $\mathrm{U}$ & $2(\mathrm{~B}, \mathrm{~S})$ & U.S. \\
\hline JIMM490 & $\mathbf{M}$ & 49 & TAA & $\mathbf{R}$ & $13(6 \mathrm{C}, 2 \mathrm{~S}, \mathrm{~B}, \mathrm{G}, 2 \mathrm{~A}, \mathrm{U})$ & U.S. \\
\hline JIMM492 & $\mathbf{M}$ & 79 & AAA & 0 & 1 (B) & U.S. \\
\hline JIMM497 & $F$ & 73 & TAA & o & $3(3 B)^{1}$ & U.S. \\
\hline JIMM498 & $\mathbf{M}$ & 71 & AAA & 0 & $2(\mathrm{~F}, \mathrm{~N})^{\prime}$ & U.S. \\
\hline JIMM499 & $\mathbf{M}$ & 46 & IA, TAA & $\mathbf{O}, \mathbf{R}$ & 0 & Haitian \\
\hline JIMM543 & $\mathbf{M}$ & 25 & TAA & $\mathbf{R}$ & $2(F, G)$ & Finnish \\
\hline
\end{tabular}

* At the time of diagnosis.

‡ Abbreviations: AAA, abdominal aortic aneurysm; TAA, thoracic aortic aneurysm; MAA, multiple aortic aneurysms; IIA, iliac artery aneurysm; IA, intracranial artery aneurysm.

Status of aneurysm at the time of diagnosis. Abbreviations: $U$, dilation detected by ultrasonography; $O$, elective operation; $R$, rupture; CT, computerized tomography. "Number of affected family members in addition to the proband. Abbreviations: S, sister; B, brother; F, father; M, mother; D, daughter; So, son; G, grandparent; C, cousin; $U$, uncle; $A$, aunt; $N$, niece or nephew.

'Some members in the family have intracranial aneurysms.

four family members, 1 patient had five family members, 1 patient had nine family members, and another patient had 13 affected family members. The age of the patients at the time of diagnosis varied between 18 and $85 \mathrm{yr}$ (mean \pm SD
$=60.3 \pm 14.1)$. Among the 54 patients studied there were 43 males and 11 females. The males were between 18 and $79 \mathrm{yr}$ of age at the time of diagnosis (mean $\pm \mathrm{SD}=59.3 \pm 13.9)$. The females were between 34 and 85 yr of age at the time of diagno- 
Table II. Oligonucleotide Primers Used to Amplify the Coding Sequences of the a1(III) Triple-Helical Domain

\begin{tabular}{|c|c|c|c|c|}
\hline $\begin{array}{l}\text { PCR } \\
\text { product }\end{array}$ & $\begin{array}{c}\text { Primer } \\
\text { name }\end{array}$ & Primer sequence & $\begin{array}{c}\text { Primer } \\
\text { location* }\end{array}$ & $\begin{array}{c}\text { Size of } \\
\text { PCR product }\end{array}$ \\
\hline & & & & $b p$ \\
\hline \multirow[t]{2}{*}{1} & III-1 & GCCGTCTAGACTGGTCCTCAGAACTATTCT & $436-456$ & 1026 \\
\hline & III-2 & CGCAAGCTTAGCTCCTGGAAGCCCATTTGC & $1423-1443$ & \\
\hline \multirow[t]{2}{*}{$2 \mathrm{~A}$} & III-3 & GCCGTCTAGAAGAATGGTGCCAAAGGAGAG & $1305-1326$ & 688 \\
\hline & III-32 & CGCGAATTCTTCCCCAGGTTTTCCATTTTCT & $1954-1974$ & \\
\hline \multirow[t]{2}{*}{ 2B } & III-25 & CGCGGATCCAGTCAAGGATAAAGTGGTCGA & $1666-1686$ & 562 \\
\hline & III-4 & CGCAAGCTTGACTTCCAAGACCTCCTCTTT & $2189-2209$ & \\
\hline \multirow[t]{2}{*}{3} & III-5 & GCCTCTAGACCACAAGGATTACAAGGCTTG & $1909-1929$ & 1067 \\
\hline & III-6 & CCCGCAAGCTTAGCTCCTGGTTTCCCACTTT & $2936-2955$ & \\
\hline \multirow[t]{2}{*}{4} & III-13 & CGGAATTCTTGGGATTGCTGGGATCACT & $2839-2859$ & 933 \\
\hline & III-14 & CGGAATTCATCAGGACTAATGAGGCTTTC & $3736-3757$ & \\
\hline
\end{tabular}

${ }^{*}$ Location in cDNA sequence, nucleotide numbers according to Ala-Kokko et al. (36).

sis ( mean $\pm \mathrm{SD}=63.3 \pm 15.0$ ), and all females had at least one additional blood relative who had the disease.

A majority (46 of 54) of the patients had aneurysm(s) in the abdominal aorta (see Table I). There were, however, six patients with a thoracic aortic aneurysm. In addition, three patients with intracranial aneurysms were included in the study because they had family members with aortic aneurysms. One of these cases was JIMM279 who had an intracranial aneurysm at the age of $50 \mathrm{yr}$ and whose sister also had an intracranial aneurysm and the daughter of the sister had a dissecting aortic aneurysm at the age of $25 \mathrm{yr}$.

Four patients had aneurysms both in cranial arteries and in

Table III. Oligonucleotide Primers Used for Direct Sequencing of the PCR Products

\begin{tabular}{|c|c|c|}
\hline PCR product & Primer name & Primer sequence \\
\hline \multirow[t]{7}{*}{1} & SP38 & CTT GCC ATC TTC GCC TTT AGC T \\
\hline & SP12B & CTC CTT TGG CAC CAT TCT TA \\
\hline & FS8 & ACC CAT TTC GCC TTT AC \\
\hline & FS2 & GCC TTC GAA TTG TCC AGG GGC ACC ATT TGA \\
\hline & SP41 & CCT CGA GCA CCG TCA TTA \\
\hline & SP11 & CAT TTC GTC CAT CGA AG \\
\hline & SP22 & CTA CCT GAT TCT CAA TCT TTT \\
\hline $1 R$ & JEJ-1 & CCT GGA CTG ATG GGA GCC CG \\
\hline \multirow[t]{4}{*}{$2 \mathrm{~A}$} & SP36 & TGT GTC TCC TTT GTC ACC ACC A \\
\hline & SP39 & GCC ACC TCG TTC TCC ATT CTT A \\
\hline & SP2 & CGG GCA TGC CCC TCA TT \\
\hline & SP13B & CAC TTT CTC CTT GAC TT \\
\hline \multirow[t]{2}{*}{ 2B } & ALA2194 & GGG GAC CAG CTC CAC CTC T \\
\hline & SP9 & CAA GCC TTG TAA TCC TT \\
\hline \multirow[t]{7}{*}{3} & SP40 & ACT TTC ACC CTT GAC ACC CTG A \\
\hline & SP15B & GCA CCA GGC GAT CTC TTC TCT \\
\hline & SP30 & CCT GGG TTA CCA TTA CTA CC \\
\hline & SP4 & GGG CCT CCT TCA CCT TT \\
\hline & SP31 & CCA GTT TCA CCT CTC TCA C \\
\hline & SP19 & GAC TTC CAA GAC CTC CTC TTT C \\
\hline & SP14 & САС ССТ ТТС СТС СТТ CG \\
\hline \multirow[t]{7}{*}{4} & SP42 & CTA ATG AGG CTT TCT ATT TGT \\
\hline & SP16 & ATG GCA GCG GCT CCA AC \\
\hline & SP43 & CCT GGG GAG CCC TCA GAT \\
\hline & SP17 & CCG ATT GCA CCC TGC TG \\
\hline & SP7 & CTG TTT CAC CTT TGT \\
\hline & SP33 & ACC ACG ATC ACC CTT GCC A \\
\hline & SP44 & TCC AGG TTC ACC AGC TGT A \\
\hline
\end{tabular}

The PCR product number refers to the numbers presented in Table II. The sequencing primers used here generate antisense sequences, except primer JEJ-1 which generates sense sequences with PCR-product $1 R$. 




Figure 1. Autoradiogram of a DNA sequencing gel. To facilitate the interpretation of results, G reactions from six (lanes 1-6) different individuals were loaded adjacent to each other, followed by $\mathrm{A}, \mathrm{T}$, and $\mathrm{C}$ reactions, in this order, from the same individuals. Lane T4 has an extra band (arrow), indicating the presence of $\mathrm{G}$ to $\mathrm{T}$ change in one allele of cell line JIMM498. The sequence is in antisense orientation.

the aorta. Two patients had iliac artery aneurysms. Six individuals with abdominal or thoracic aortic aneurysms had one or more family members with intracranial aneurysms. At the time of the diagnosis the aortic aneurysm had ruptured in 7/54 patients. 36 patients underwent an elective operation for their aortic aneurysms. Five patients were first diagnosed by ultrasonographic examination.

DNA sequences and polymorphisms of type III collagen. The sequence analysis carried out here provided 3,232 nucleotides from each allele of the gene for type III procollagen. The region analyzed covered the coding sequences for all the 14 amino acids of the amino-terminal telopeptide, all the 1,029 amino acids of the triple-helical domain, all the 25 amino acids of the carboxyterminal telopeptide, and 8 of the 246 amino acids of the carboxy-terminal propeptide. The sequences for the amino-terminal propeptide and most of the carboxy-terminal propeptide were not analyzed. These amino acid sequences are cleaved off from the procollagen before the fibril formation can occur and they are, therefore, not present in the mature form of collagen (20).

Only two sequence variations were found in the 54 individuals ( Table IV). Cell line JIMM407 had a G to A change at nt 907. The nucleotide change converted the codon at amino acid position 136 from GGG for glycine to AGG, a codon for arginine. The mutation was confirmed using genomic DNA isolated from the patient's fibroblasts (not shown). The mutation was not found in any of additional 127 individuals sequenced in the laboratory.

The patient was an 18-yr-old black male without any prior relevant medical history (43). He had suddenly developed par- aparesis and bilateral loss of pulses below the waist (43). An aortogram disclosed a dissecting aneurysm of the entire aorta and obstruction of blood flow below the renal arteries (43). His autopsy findings revealed dissecting aortic aneurysm and generalized fibromuscular dysplasia (43). His father had died at the age of $36 \mathrm{yr}$ in a car accident and no affected relatives were available for DNA testing. His mother did not have the mutation, but the patient's three unaffected sibs were found to have the same mutation. Ultrasound examination of the aorta on the sibs (aged 21,20 , and $16 \mathrm{yr}$ ) did not reveal any abnormalities.

In the cell line JIMM498 a C to A change was found at nt 2002, changing the codon CCT for proline at amino acid position 501 to ACT, a codon for threonine (Fig. 1). PCR on genomic DNA from the patient indicated that the sequence variant was real and not a PCR artifact (not shown). The change was not found in any of the other 127 individuals sequenced in the laboratory. The patient was $70 \mathrm{yr}$ old, when he was operated on for an abdominal aortic aneurysm. His father also had an aortic aneurysm but was deceased and no material was available for DNA testing. The patient's nephew (a son of the patient's younger brother) was operated on for an intracranial aneurysm at the age of $28 \mathrm{yr}$. This nephew had the mutation. DNA analysis revealed that the change was also present in the patient's two unaffected brothers aged 68 and $73 \mathrm{yr}$, the younger of which had been examined by sonography and no aortic aneurysm was found. Thus, two unaffected and two affected individuals in the family had the DNA change. The change was, therefore, probably not the cause of the aneurysms.

When analyzing the sequencing results from the 54 individ- 
Table IV. Sequence Variations Detected in the 54 Patients

\begin{tabular}{llll}
\hline $\begin{array}{c}\text { Cell line } \\
\text { code }\end{array}$ & \multicolumn{1}{c}{ Location* } & Nature & Occurrence \\
\hline JIMM407 & nt 907 (E14) & Gly136 $\rightarrow$ Arg & $1 / 128^{\S}$ \\
JIMM498 & nt 2002(E30) & Pro501 $\rightarrow$ Thr & $1 / 128^{\S}$ \\
\hline
\end{tabular}

* E14, exon 14 of the gene for type III procollagen; E30, exon 30 of the gene for type III procollagen.

${ }^{\ddagger}$ Numbering starts at the beginning of the triple-helical domain of type III procollagen.

8 Only one patient was found to have the base change. A total of 127 other unrelated individuals that included the 49 other aortic aneurysm patients presented here, 55 patients with intracranial aneurysms, 5 patients with the EDS type IV, 4 patients with osteogenesis imperfecta, 5 patients with the EDS (without subclassification), 8 patients with a variety of connective tissue abnormalities without any specific diagnosis, and one apparently healthy individual were sequenced in the laboratory.

uals, special care was taken to record data on known polymorphic regions of the type III collagen. The three polymorphisms that have been found previously in the coding region of type III collagen are at positions nt 1851 ( Wu and Kuivaniemi, unpublished results), 2092 (41), and 2244 (42). 40 of the 54 individuals were found to be heterozygous for at least one of the polymorphisms ( Table V), indicating that both of the alleles of the gene for type III procollagen were expressed at the mRNA level. The polymorphism analysis was also carried out on genomic DNA samples isolated from the cultured skin fibroblasts of the patients. The results obtained from the analysis showed that the 40 individuals that were heterozygous in their cDNA for one or more polymorphisms were also heterozygous in their genomic DNA. The results also showed that the 14 individuals who did not show any heterozygosity in the cDNA sequences were homozygous on their genomic DNA for all three markers studied.

\section{Discussion}

There are two general approaches using DNA techniques that can be used to identify the gene harboring the mutations causing aortic aneurysms. The first approach is to carry out linkage studies using markers that have been mapped to a particular locus on the genome and are used to test whether or not the marker is co-inherited with aortic aneurysms in families. Linkage can be established whenever the phenotype and genotype of related individuals is analyzed. Therefore, linkage can be established by analyzing large families. There are, however,

Table V. Heterozygosity of the 54 Patients at Three Polymorphic Sites Located in the Coding Sequences of Type III Collagen

\begin{tabular}{cc}
\hline Location of polymorphism & Number of heterozygous individuals \\
\hline nt 1851 & 18 \\
nt 2092 & 22 \\
nt 2244 & 21
\end{tabular}

Total number of patients heterozygous for at least one of the markers: 40. several problems in the approach when studying a late-onset disease such as aortic aneurysms. It is rare to find large index families that have more than two generations of living, affected members so that pertinent samples can be obtained. In addition, diagnosis is a problem, inasmuch as the data on the incidence of aneurysms in the population indicate that few individuals develop aneurysms before the age of $50 \mathrm{yr}$ and that the incidence increases with age.

The second approach, the candidate gene approach, involves the analysis of a candidate gene for absence or presence of mutations. The modern techniques of molecular biology have made the approach feasible (44). Here we were able to get definitive results from detailed DNA sequencing analysis of the gene for type III procollagen of 54 individuals from 50 unrelated families. The analysis revealed a mutation in obligatory glycine $(20,21)$ in one patient. The substitution of arginine for a glycine at amino acid position 136 in type III procollagen is likely to disrupt the triple-helical structure of the protein and make the protein less stable $(20,21)$. The finding represents a second example of a glycine to arginine mutation in the type III procollagen causing aortic aneurysms in patients without other signs of the EDS. The first report was a substitution of arginine for glycine at amino acid position 619 of the triple-helical domain of type III procollagen (25).

The other sequence variant detected in another patient substituted threonine for proline in a Y position of the Gly-X-Y repeat of collagen triple-helical domain $(20,21)$. Substitution of threonine for a Y-position proline is not likely to be destabilizing since six of the 14 threonines normally found in the type III collagen triple-helical domain (36) occupy the Y position. In addition, threonine and proline have been exchanged during evolution of collagens (45). Also, the mutation was present in the patient's apparently unaffected brothers suggesting that the mutation was an infrequent sequence variant. The results, therefore, indicate that mutations in the triple-helical domain of type III procollagen are the cause of $\sim 2 \%(1 / 50)$ of aortic aneurysms. In addition, the results suggest that mutations in the promoter region or other control regions of the gene for type III procollagen are not a common cause for aneurysms, in that at least 40 of the 50 patients studied here had mRNA that was derived from both alleles of the gene.

From a theoretical perspective, DNA sequencing provides a complete record of all of the bases that comprise a gene or its coding sequence. Therefore, DNA sequencing will lead to the detection of all mutations in a target region. Furthermore, it makes it possible to exclude definitively the region from those that possibly contain mutations. Our results demonstrate that sequencing has become a feasible approach not only to establish rapidly and definitively whether or not a candidate gene harbors the mutations causing a disease phenotype, but also to determine what fraction of affected individuals have a mutation in the particular candidate gene. This approach could, therefore, be used to establish whether or not other genes that have been suggested as candidate genes, such as the genes for fibrillin (17), elastin (31), collagenase (26), elastase (27), or tissue inhibitor of metalloproteinase (29), harbor mutations causing aortic aneurysms.

\section{Acknowledgments}

The authors thank Maria Hervada-Page for collecting some of the patient information, and Gi-Chung Chen, Nasrin Rafi, and Kanger Wu for culturing cells. 
This work was supported in part by grants from the National Institutes of Health (HL 45996 and AR 38188), the American Heart Association, Southeastern Pennsylvania Affiliate, the Lucille P. Markey Charitable Trust, and the March of Dimes/Birth Defects Foundation.

\section{References}

1. McKusick, V. A. 1972. Heritable Disorders of Connective Tissue. C. V. Mosby Co., St. Louis, MO. 61-223, 292-371.

2. Clifton, M. A. 1977. Familial abdominal aortic aneurysms. Br. J. Surg. 64:765-766

3. Tilson, M. D., and M. R. Seashore. 1984. Human genetics of the abdominal aortic aneurysm. Surg. Gynecol. Obstet. 158:129-132.

4. Tilson, M. D., and M. R. Seashore. 1984. Fifty families with abdominal aortic aneurysms in two or more first-order relatives. Am. J. Surg. 147:551-553.

5. Norrgård, Ö., O. Rais, and K. A. Ängquist. 1984. Familial occurrence of abdominal aortic aneurysms. Surgery. 95:650-656.

6. Johansen, K., and T. Koepsell. 1986. Familial tendency for abdominal aortic aneurysms. JAMA (J. Am. Med. Assoc.). 256:1934-1936.

7. Powell, J. T., and R. M. Greenhalgh. 1987. Multifactorial inheritance of abdominal aortic aneurysm. Eur. J. Vasc. Surg. 1:29-31.

8. Cole, C. W., G. G. Barber, A. G. Bouchard, N. V. McPhail, C. Roberge, W. G. Waddell, and J. L. Wellington. 1989. Abdominal aortic aneurysm: consequences of a positive family history. Can. J. Surg. 32:117-120.

9. Darling, R. C. III, D. C. Brewster, R. C. Darling, G. M. LaMuraglia, A. C. Moncure, R. P. Cambria, and W. M. Abbott. 1989. Are familial abdominal aortic aneurysms different? J. Vasc. Surg. 39-43.

10. Bengtsson, H., Ö. Norrgård, K. A. Ängquist, O. Ekberg, L. Öberg, and D. Bergqvist. 1989. Ultrasonographic screening of the abdominal aorta among siblings of patients with abdominal aortic aneurysms. Br. J. Surg. 76:589-591.

11. Webster, M. W., R. E. Ferrell, P. L. St. Jean, P. P. Majumder, S. R. Fogel, and D. L. Steed. 1991. Ultrasound screening of first-degree relatives of patients with an abdominal aortic aneurysm. J. Vasc. Surg. 13:9-14.

12. Majumder, P. P., P. L. St. Jean, R. E. Ferrell, M. W. Webster, and D. L. Steed. 1991. On the inheritance of abdominal aortic aneurysm. Am. J. Hum Genet. 48:164-170.

13. Reilly, J. M., and M. D. Tilson. 1989. Incidence and etiology of abdominal aortic aneurysms. Surg. Clin. North Am. 69:705-711.

14. Lee, B., M. Godfrey, E. Vitale, H. Hori, M.-G. Mattei, M. Sarfarazi, P. Tsipouras, F. Ramirez, and D. W. Hollister. 1991. Linkage of Marfan syndrome and a phenotypically related disorder to two different fibrillin genes. Nature (Lond.). 352:330-334.

15. Dietz, H. C., G. R. Cutting, R. E. Pyeritz, C. L. Maslen, L. Y. Sakai, G. M Corson, E. G. Puffenberger, A. Hamosh, E. J. Nanthakumar, S. M. Curristin, et al. 1991. Marfan syndrome caused by a recurrent de novo missense mutation in the fibrillin gene. Nature (Lond.). 352:337-339.

16. Kainulainen, K., L. Y. Sakai, M. Pope, A. Child, L. Puhakka, L. Ryynänen, A. Palotie, I. Kaitila, and L. Peltonen. 1992. Two mutations in Marfan syndrome resulting in truncated fibrillin polypeptides. Proc. Natl. Acad. Sci. USA. 89:5917-5921.

17. McKusick, V. A. 1991. The defect in Marfan syndrome. Nature (Lond.). 352:279-281

18. Dobrin, P. B., T. H. Schwarcz, and R. Mrkvicka. 1990. Longitudinal retractive force in pressurized dog and human arteries. J. Surg. Res. 48:116-120.

19. Mayne, R. 1987. Vascular connective tissue. Normal biology and derangement in human diseases. In Connective Tissue Disease. Molecular Pathology of the Extracellular Matrix. J. Uitto and A. J. Perejda, editors. Marcel Dekker Inc., New York. 163-183.

20. Prockop, D. J. 1990. Mutations that alter the primary structure of type I collagen. The perils of a system for generating large structures by the principle of nucleated growth. J. Biol. Chem. 265:15349-15352.

21. Kuivaniemi, H., G. Tromp, and D. J. Prockop. 1991. Mutations in collagen genes: causes of rare and some common diseases in humans. FASEB J. 5:2052-2060.

22. Deak, S. B., J. J. Ricotta, T. J. Mariani, S. T. Deak, M. A. Zatina, J. W. Mackenzie, and C. D. Boyd. 1992. Abnormalities in the biosynthesis of type III procollagen in cultured skin fibroblasts from two patients with multiple aneurysms. Matrix. 12:92-100.

23. Kontusaari, S., G. Tromp, H. Kuivaniemi, R. L. Ladda, and D. J. Prockop. 1990. Inheritance of an RNA splicing mutation $\left(G^{+1 \text { IVS20 }}\right)$ in the type
III procollagen gene ( $\mathrm{COL} 3 \mathrm{Al}$ ) in a family with aortic aneurysms and easy bruisability: phenotypic overlap between familial arterial aneurysms and the EhlersDanlos syndrome type IV. Am. J. Hum. Genet. 47:112-120.

24. Beighton, P. 1970. The Ehlers-Danlos Syndrome. William Heinemann, Ltd., London. $194 \mathrm{pp}$.

25. Kontusaari, S., G. Tromp, H. Kuivaniemi, A. M. Romanic, and D. J. Prockop. 1990. A mutation in the gene for type III procollagen (COL3A1) in a family with aortic aneurysms. J. Clin. Invest. 86:1465-1473.

26. Busuttil, R. W., A. M. Abou-Zamzam, and H. I. Machleder. 1980. Collagenase activity of the human aorta: a comparison of patients with and without abdominal aortic aneurysms. Arch. Surg. 115:1373-1378.

27. Cannon, D., and R. Read. 1982. Blood elastolytic activity in patients with aortic aneurysms. Ann. Thorac. Surg. 34:10-15.

28. Cohen, J. R. I. Sarfati, I. Ratner, and M. D. Tilson. 1990. Alpha-1 antitrypsin phenotypes in patients with abdominal aortic aneurysms. J. Surg. Res 49:319-321.

29. Brophy, C. M., B. Sumpio, J. M. Reilly, and M. D. Tilson. 1991. Decreased tissue inhibitor of metalloproteinases (TIMP) in abdominal aortic aneurysmal tissue: a preliminary report. J. Surg. Res. 50:653-657.

30. Kuivaniemi, H., G. Tromp, and D. J. Prockop. 1991. Genetic causes of aortic aneurysms. Unlearning at least part of what the textbooks say. J. Clin. Invest. 88:1441-1444.

31. Menashi, S., J. S. Campa, R. M. Greenhalgh, and J. T. Powell. 1987. Collagen in abdominal aortic aneurysm: typing, content, and degradation. $J$. Vasc. Surg. 6:578-582.

32. Maniatis, T., E. F. Fritsch, and J. Sambrook. 1982. Molecular Cloning: A Laboratory Manual. Cold Spring Harbor Laboratory, Cold Spring Harbor, NY.

33. Loidl, H. R., J. M. Brinker, M. May, T. Pihlajaniemi, S. Morrow, J. Rosenbloom, and J. C. Myers. 1984. Molecular cloning and carboxylpropeptide analysis of human type III procollagen. Nucleic Acids Res. 12:9383-9394.

34. Chu, M.-L., D. Weil, W. de Wet, M. Bernard, M. Sippola, and F. Ramirez. 1985. Isolation of cDNA and genomic clones encoding human pro- $\alpha$ ( III) collagen: partial characterization of the 3'-end region of the gene. J. Biol. Chem. 260:4357-4363.

35. Miskulin, M., R. Dalgleish, B. Kluve-Beckerman, S. I. Rennard, P. Tolstoshev, M. Brantly, and R. G. Crystal. 1986. Human type III collagen gene expression is coordinately modulated with the type I collagen genes during fibroblast growth. Biochemistry. 25:1408-1413.

36. Ala-Kokko, L., S. Kontusaari, C. Baldwin, H. Kuivaniemi, and D. J. Prockop. 1989. Structure of cDNA clones coding for the entire prepro $\alpha$ (III) chain of human type III procollagen: differences in protein structure from type I procollagen and conservation of codon preferences. Biochem. J. 260:509-516.

37. Tromp, G., H. Kuivaniemi, H. Shikata, and D. J. Prockop. 1989. A single base mutation that substitutes serine for glycine 790 of the $\alpha 1$ (III) chain of type III procollagen exposes an arginine and causes Ehlers-Danlos syndrome IV. $J$. Biol. Chem. 264:1349-1352.

38. Tromp, G., H. Kuivaniemi, C. Stolle, F. M. Pope, and D. J. Prockop. 1989. Single base mutation in the type III procollagen gene that converts the codon for glycine 883 to aspartate in a mild variant of Ehlers-Danlos syndrome IV. J. Biol. Chem. 264:19313-19317.

39. Saiki, R. K., S. Scharf, F. Faloona, K. B. Mullis, G. T. Horn, H. A. Erlich, and N. Arnheim. 1985. Enzymatic amplification of $\beta$-globin genomic sequences and restriction site analysis for diagnosis of sickle cell anemia. Science (Wash. DC). 230:1350-1354.

40. Sanger, F., S. Nicklen, and A. R. Coulson. 1977. DNA sequencing with chain-terminating inhibitors. Proc. Natl. Acad. Sci. USA. 74:5463-5467.

41. Zafarullah, K., C. Kleinert, G. Tromp, H. Kuivaniemi, S. Kontusaari, Y. Wu, A. Ganguly, and D. J. Prockop. 1990. G to A polymorphism in exon 31 of the COL3A1 gene. Nucleic Acids Res. 18:6180.

42. Tromp, G., C. Kleinert, H. Kuivaniemi, and D. J. Prockop. 1991. C to T polymorphism in exon 33 of the COL3A1 gene. Nucleic Acids Res. 19:681.

43. Gatalica, Z., Z. Gibas, and A. Martinez-Hernandez. 1992. Dissecting aortic aneurysm as a complication of generalized fibromuscular dysplasia. Hum. Pathol. 23:586-588.

44. Tromp, G., and H. Kuivaniemi. 1992. Identification of familial aortic aneurysms using DNA technique. In Technologies in Vascular Surgery. J. S. T. Yao, and W. H. Pearce, editors. W. B. Saunders Co., Philadelphia. 27-39.

45. Kuivaniemi, H., Tromp, G., Chu, M.-L., and Prockop, D. J. 1988. Structure of a full-length clone for the prepro 2 (I) chain of human type I procollagen: comparison with the chicken gene confirms unusual patterns of gene conservation. Biochem. J. 253:633-640. 